\title{
Benefits of stress superposition in combined bending-linear flow splitting process
}

\author{
P. Groche ${ }^{1} \cdot$ C. Taplick ${ }^{1} \cdot$ M. Özel ${ }^{1} \cdot$ P. Mahajan ${ }^{1} \cdot$ S. Stahl ${ }^{1}$
}

Received: 20 June 2016 / Accepted: 2 November 2016 /Published online: 19 November 2016

(C) The Author(s) 2017. This article is published with open access at Springerlink.com

\begin{abstract}
Linear flow splitting is a multi-station sheet-bulk metal forming process which allows continuous production of bifurcated profiles without joining, lamination or external heating of sheet metal. This process induces high hydrostatic stresses in the forming zone which leads to an elevated formability of the workpiece material. The aim of this research is to bend linear flow split profiles in transverse direction in a continuous manner. This is achieved by combining the linear flow splitting process with a continuous bending process. An analytical and a numerical model are described in this paper which predict bending moments for different radii. Results from both models are validated with experimental results. It is found that combining the linear flow splitting with a bending process leads to a severe reduction in the bending moments due to superposition of stresses in the forming zone. The superposition maintains the cross sectional shape of the bent profiles.
\end{abstract}

Keywords Linear flow splitting · Finite element analysis · Bending $\cdot$ Springback

\section{Nomenclature}

Symbol unit Explanation

$a_{1 f} \quad[\mathrm{~mm}]$ Width of Section 1

$a_{2 f} \quad[\mathrm{~mm}]$ Width of Section 2

$a_{\text {total }} \quad[\mathrm{mm}]$ Flange width

$b_{4 e l} \quad[\mathrm{~mm}]$ Height of Section 4

$b_{n} \quad[\mathrm{~mm}]$ Substitute for height

\section{P. Groche}

groche@ptu.tu-darmstadt.de

Institute for Production Engineering and Forming Machines, Technische Universität Darmstadt, 64287 Darmstadt, Germany
$R_{b} \quad$ [mm] Bending radius

$b_{\text {total }} \quad[\mathrm{mm}]$ Total height (analytical)

$D_{S p R} \quad$ [mm] Diameter splitting roll

$D_{\text {SuR }} \quad[\mathrm{mm}]$ Diameter supporting roll

E $\quad\left[\mathrm{N} / \mathrm{mm}^{2}\right]$ Young's modulus

$E_{\text {sub }} \quad\left[\mathrm{N} / \mathrm{mm}^{2}\right]$ Substitute modulus

$h \quad[\mathrm{~mm}]$ Radius at supporting roll

$h_{n} \quad[\mathrm{~mm}]$ Substitute for height

$J_{z} \quad\left[\mathrm{~mm}^{4}\right]$ Second moment of area

$k_{f} \quad\left[\mathrm{~N} / \mathrm{mm}^{2}\right]$ Flow stress

$l_{\text {SuR }} \quad[\mathrm{mm}]$ Width of supporting roll

$M_{b} \quad[\mathrm{Nm}]$ Bending moment

$R \quad[\mathrm{~mm}]$ Radius at splitting roll

$s_{O} \quad[\mathrm{~mm}]$ Web width

$s_{f} \quad[\mathrm{~mm}]$ Flange width

$y_{F} \quad[\mathrm{~mm}]$ Distance from neutral axis to boundary elastic plastic region

$y_{\text {inc }} \quad[\mathrm{mm}]$ Incremental in-feed

$y_{\text {total }} \quad[\mathrm{mm}]$ Total in-feed

$\alpha \quad\left[{ }^{\circ}\right]$ Supporting roll angle

$\alpha_{s} \quad\left[{ }^{\circ}\right]$ Splitting roll angle

\section{Introduction}

Demand for high strength steel profiles has increased strongly due to requirements to reduce fuel consumption by weight reduction [1]. This is indicated by a statistic of the fabrication of flat rolled steel within Germany which has quintupled since the 1950s [2]. Roll forming has been established in the manufacturing industry for numerous years because it fulfils the requirements of high volume production and low costs. The geometrical flexibility can be increased by preforms produced through the linear flow splitting process $[2,3]$.

In a linear flow splitting process, forces are applied by splitting rolls on a metal sheet and at the same time compressive 
stresses are induced through supporting rolls on the sheet surface. The multi-axial compressive stresses increase the formability of the material at room temperature. By arranging the rolls in a multi-station line, a continuous production of bifurcated profiles from the sheet metal is possible [5]. The linear flow split profiles can be used as a semi-finished product which is shaped in the web and the flange zone by roll forming [6]. Furthermore, it is also possible to use the roll formed linear flow split profile as a preform for hydroforming [7, 8]. Many products create a demand for curved profiles. Therefore, a subsequent step of the previous development is to manufacture bent profiles in a continuous way. A number of technologies are available to bend the profiles such as three-roll bending, stretch bending, laser bending (Fig. 1).

Major challenges in bending high strength steel profiles result from the limited formability, the large and uncertain springback and the high tool loads. As a characteristic of linear flow splitting processes, a significant increase of strength is observed in the flanges of the profile [12]. Therefore, linear flow split profiles manufactured from high strength steel are expected to encounter higher springback and lower formability than conventional mild steel profiles. The objective of this study is to propose a method which will allow for bending linear flow split profiles with a constant cross-section in a continuous manner without any expensive tool change costs. Further objectives are to propose an analytical and a FE model to evaluate bending moments required to bend the profile and to investigate shape accuracy after bending.

\section{State of the art}

\section{Linear flow splitting}

Linear flow splitting is a multi-station cold forming process for manufacturing bifurcated profiles without joining or lamination of material in a continuous way. Each station consists of a pair of obtuse angled splitting and supporting rolls as shown in Fig. 2 (a). The produced product is an axisymmetric profile characterized by a web and flanges Fig. 2 (b). A metal sheet is moved with the help of supporting rolls and forming is carried out by splitting rolls. In a flow splitting line, two splitting rolls in each station are arranged at a distance in transverse direction ( $Y$-direction) which is reduced from station to station by an amount " $y_{i n c}$ " (Fig. 2 c). The width of the supporting rolls in corresponding forming stations is also reduced.

Fig. 1 Possible applications of bent flow split profiles [9-11]

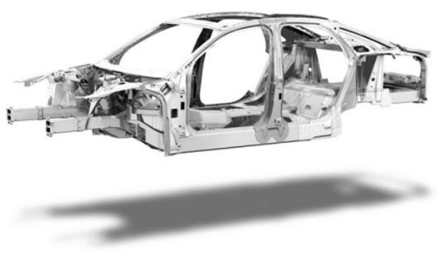

Therefore, at each forming station, the surface area of the sheet metal's band edge is increased by the forming operation. The metal sheet is formed incrementally until the desired geometry is achieved. In this process, combination of the splitting rolls and the supporting rolls induce high hydrostatic stresses in the forming zone which results in better formability and an ultrafine grain (UFG) microstructure [12].

\section{Profile bending}

Bending is one of the oldest and most frequently used forming processes. The bending of profiles allows an engineer to save space, produce aerodynamic advantageous shapes and even neglect expensive joints [13-15]. The varying requirements result in a wide range of different bending technologies. The bending processes with rotary as well as straight tool movement are divided into bending with form-bound contour or kinematically defined bending contour and thermally induced bending processes [16].

Most analytical calculations of bending refer to the studies of Ludwik [17] whose simplifications allow the direct allocation of stress to strain according to stress-strain curves depending on the material $[18,19]$. The strain is dispersed symmetrically perpendicular to the non-elongated fibre (Fig. 3).

The bending moment can be calculated by integrating stresses along the cross section. The sum of the elastic and the plastic moment results in the bending moment (eq. 1).

$M_{b}=M_{b, \text { elastic }}+M_{b, \text { plastic }}=2 \int_{y=0}^{y=y_{F}} \sigma_{x}(x)$ bydy $+2 \int_{y=y_{F}}^{y=s_{0} / 2} \sigma_{x}(y)$ bydy $(1)$

with $y_{F}=\frac{k_{f} R_{b}}{E}$

This method is adapted to profile bending under ideal conditions regarding shape, strain and material [20].

\section{Methods for bending linear flow split profiles}

\section{Requirements for bending linear flow split profiles}

The bending process of linear flow split profiles is expected to fulfil the following requirements:

1. The bending process should allow continuous forming
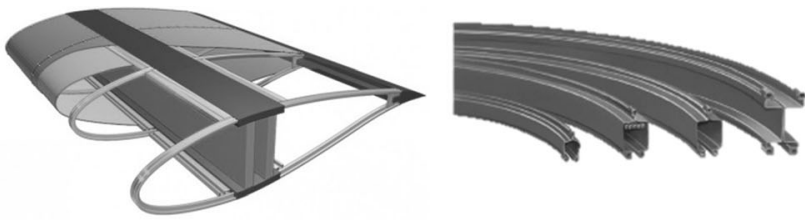


\section{Linear flow splitting station}

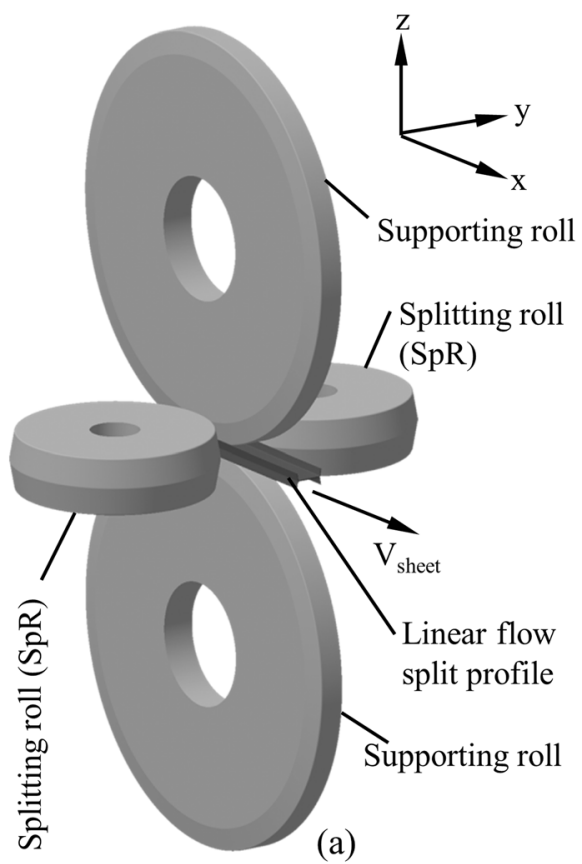

\section{Forming area and geometry}

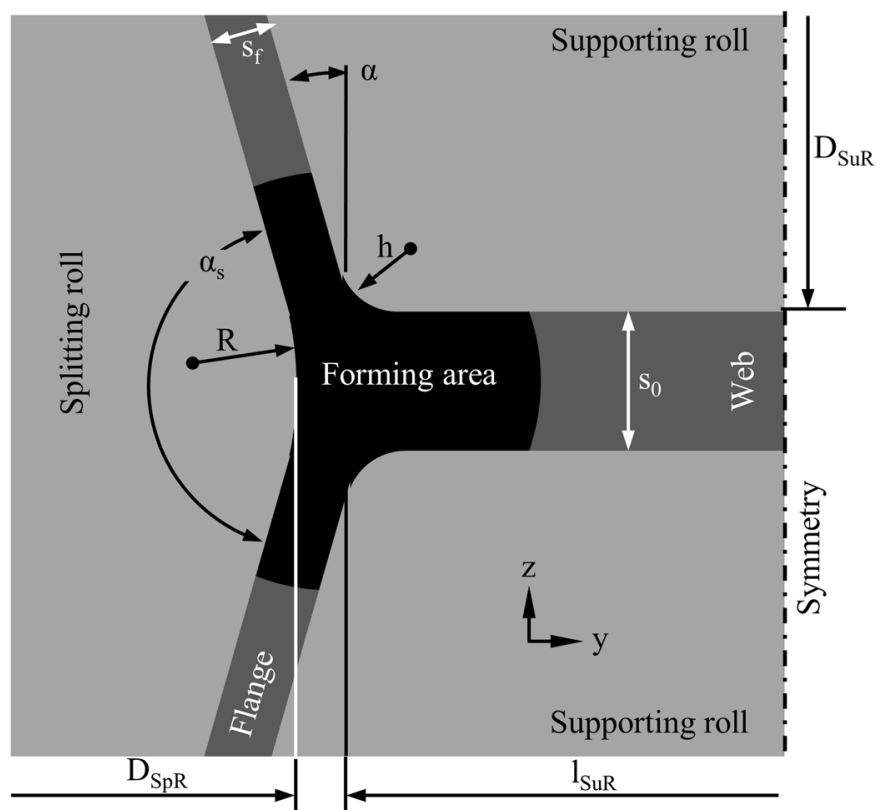

(b)

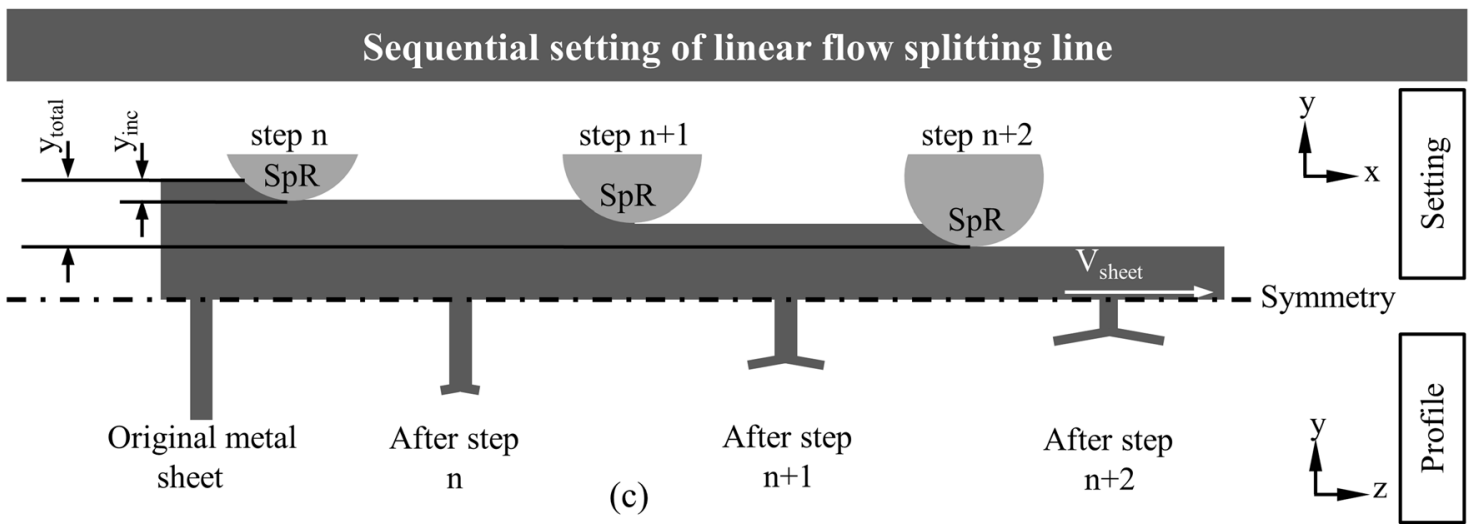

Fig. 2 Principle of linear flow splitting ( LFS)

2. Due to requirements of shape accuracy, the bending process should be easily adjustable to incorporate changes in the bending radius
3. The UFG properties in the flanges of linear flow split profiles should remain unchanged throughout the bending process
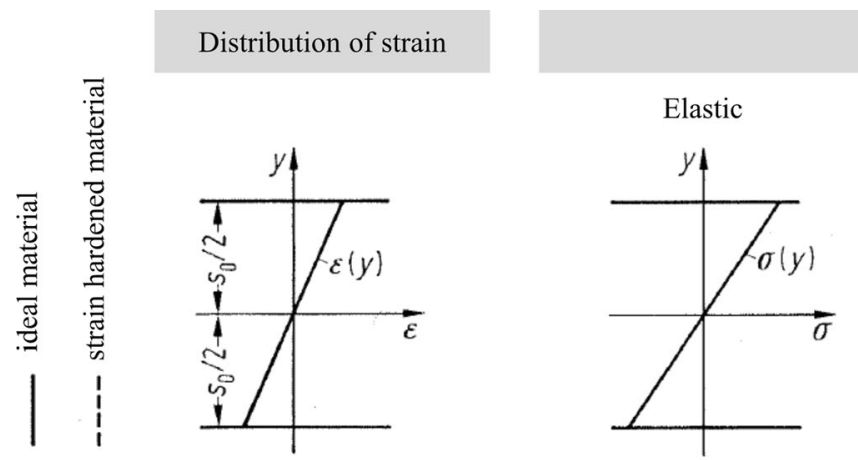

Distribution of stress
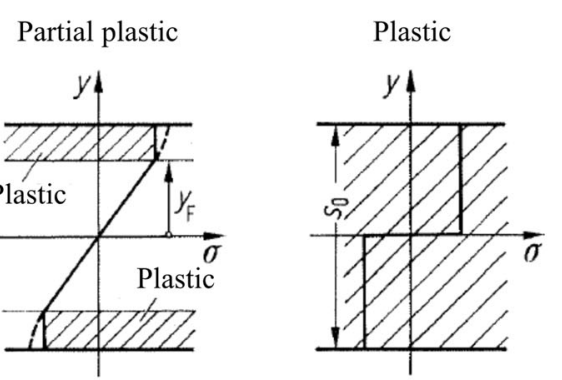

Fig. 3 Stress-strain distribution in bending [18] 
Profile bending procedures are categorized into two methods: Kinematic shaping and forming with shape defining dies. In kinematic shaping processes, the final shape of the profile is not determined by the shape of the bending tool. The final shape is rather produced by relative movements of tool and workpiece. Whereas, in forming with shape defining dies, the shape of the bending tool determines the final shape of the profile. In both procedures, the bending tool can possess a linear or rotary motion while bending a profile [19]. Due to fixed geometry of the bending tool in the forming with shape defining dies, the second requirement is violated. Thermally induced bending methods which are classified under the kinematic shaping procedure, have an influence on the microstructure of a material. Therefore, these bending methods can be excluded regarding the third requirement. As a result, only kinematic shaping bending procedures with rotary tool motion during bending satisfy all three requirements. Therefore, these methods are considered for preliminary investigations.

\section{Preliminary investigations on different bending methods}

Kinematic bending processes are flexible since the final shape of a profile is not solely defined by the shape of a bending tool, but instead defined by relative motion of the tool and the profile. To evaluate different bending methods, a numerical approach is selected. All finite element models are generated and solved by Marc Mentat software with an implicit solver. The models use 8-node hexagonal elements with a full integration and an assumed strain formulation to accurately simulate the bending behaviour [21]. For the preselection of bending processes friction is neglected. At first, the following four bending strategies for flow split profiles are considered and evaluated with numerical simulations keeping initial dimensions of the profile constant as shown in Fig. 4 (a). In the numerical simulations, the profile is made up of "RAWAEL80" material [22]. The flow stress-strain curve obtained from tensile tests is depicted in Fig.4 (a). In numerical models, material is modelled as an elastic-plastic material. The material hardening is isotropic and the von Mises yield surface and the associated flow rule are used. The bending strategies considered for investigations are quasi-static processes because the kinetic energy of the deformation does not exceed a small fraction $(5 \%$ to $10 \%)$ of its kinetic energy [23]. Therefore, to reduce computational time for all numerical models, the linear flow split profile is fixed in all three directions and rigid rolls are moved in $-\mathrm{X}$ direction as shown in Fig. 4 (b).

A. Three-roll bending In three-roll-bending, a profile is bent by three bending rolls after linear flow splitting process (Fig.4 b). The position of rolls can be adjusted according to the required radius. The process is analysed numerically for a bending radius, $R_{b}=2312.5 \mathrm{~mm}$ and material RAWAEL 80 . This bending radius results in a bending force of $F_{b}=5600 \mathrm{~N}$ and a springback factor $K=0.68(K=$ initial radius $/$ final radius) in the simulations. Although, buckling was not observed for aforementioned bending radius, there exists a high possibility of buckling under non-ideal experimental conditions [24]. Also, this high bending force can lead to high springback which makes overbending compensation errorprone.

B. Local rolling The purpose of this method is to thin a profile locally at a certain position on the outer side of the web. This results in local elongation of the thinned zone in the longitudinal direction. Because of these induced longitudinal strains on the outer part of the web, the profile is bent in transverse direction. To get the bending radius $\left(R_{b}=2312.5 \mathrm{~mm}\right)$, the web thickness has to be reduced by $0.24 \mathrm{~mm}$ on the outer side and a local rolling force of $F_{r}=220 \mathrm{kN}$ is required. In real processes, this high force would lead to deflection of the tool system or enforce a very stiff system. The reduced thickness of the web caused by the local rolling is another disadvantage of this bending strategy.

C. Bending after straightening station In this method, a bending roll is positioned after a straightening station. This bending roll is moved in transverse direction as per required bending radius $\left(R_{b}=2312.5 \mathrm{~mm}\right)$. This method also leads to the same disadvantages like three-roll bending. The simulation results show that springback factor in this bending strategy is 0.64 whereas a bending force $F_{b}=1000 \mathrm{~N}$ is exerted on the bending roll.

D. Bending after a linear flow splitting station In this method, after linear flow splitting, the split profile is bent by a bending roll which can be moved in both transverse and longitudinal directions as per the designed bending radius. In a linear flow splitting station, high multi-axial stresses are applied in the forming zone. Therefore, the cross-section of the profile within the forming zone is deformed plastically. The bending roll after the last splitting station applies bending moment at the forming zone which is already deformed plastically. Therefore, a very small force on bending roll is exerted whereas very high forces are exerted on the linear flow splitting station (described in Section 7).

This method shows good results regarding the required bending force and the springback factor. In the numerical simulation, a bending force of only $F_{b}=200 \mathrm{~N}$ is required to bend the targeted radius. The springback factor for this method is found to be $K=0.93$. This shows that this bending strategy can lead to less springback than all three bending methods explained before. Therefore, this bending strategy is selected and evaluated in detail in this research work. 

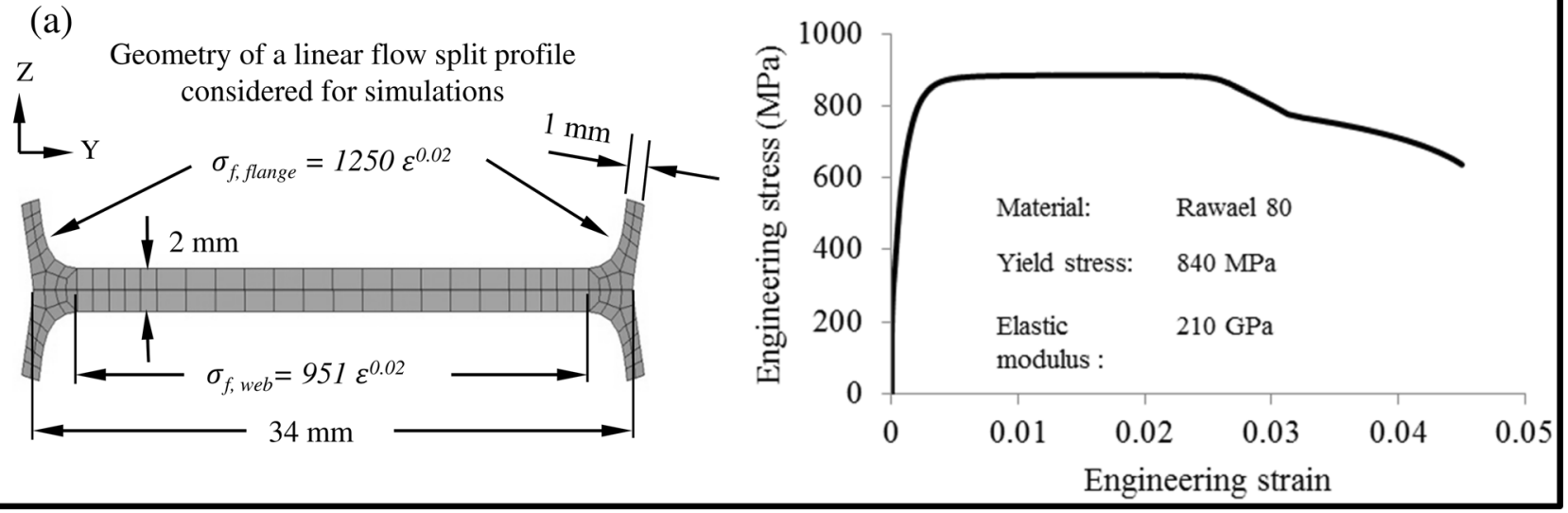

(b)

\section{Methods for continuous bending of linear flow splitting profiles}

Single process

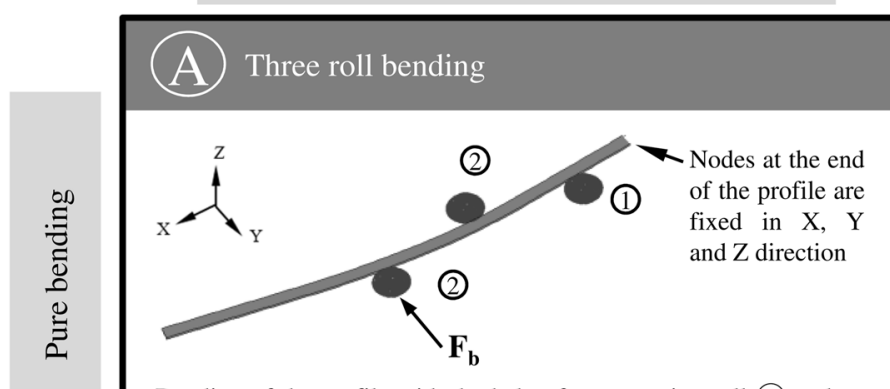

Bending of the profile with the help of a supporting roll (1) and two shifted bending rolls (2) after a linear flow splitting

\section{B Partial local rolling}

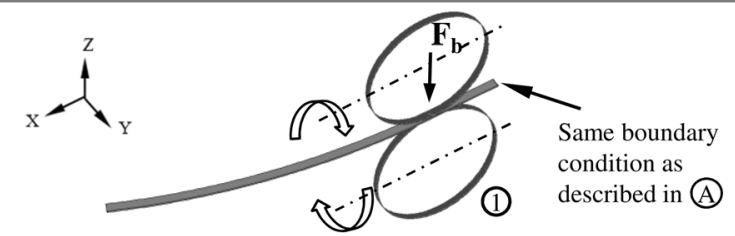

By tilting two supporting rolls (1) against each other, web is rolled out partially
Combined process

\section{Bending after straightening station}

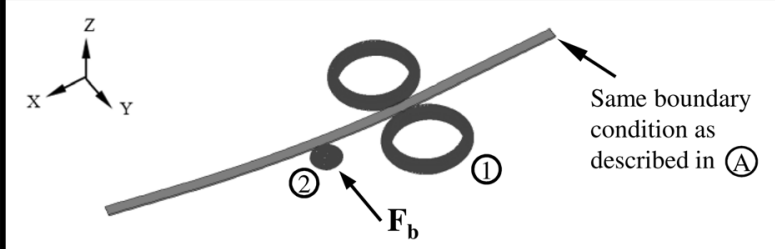

Bending of the profile with a shifted bending roll (2) after a process of straightening or a roll forming station (1)
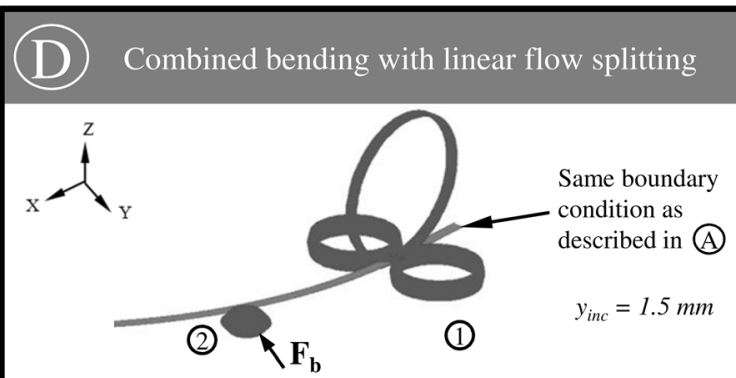

Bending of the profile due to movement of bending roll (2) in transverse direction after a linear flow splitting station (1)

Fig. 4 a Initial geometry of a profile, $\mathbf{b}$ Methods for continuous bending of linear flow split profiles

\section{Tool system and experimental work}

The presented process chain consists of the following steps:

- uncoiling of sheet material

- manufacturing of bifurcations at the band edge by linear flow splitting

- bending of the profile

- cutting into desired sections
In all investigations described in the following section, the profile is bent in transverse direction only. The tooling system consists of a blankholder to hold the bent profile in vertical direction, a bending roll with a smaller diameter than the splitting roll and a calibrated load cell to measure forces exerted on the bending roll. The bending roll is positioned at a constant distance of $Y=100 \mathrm{~mm}$ (centre to centre) from the splitting roll of the last flow splitting station as shown in Fig. 5 (b). The $X$ distance of the roll can be adjusted to obtain the designed radii. 


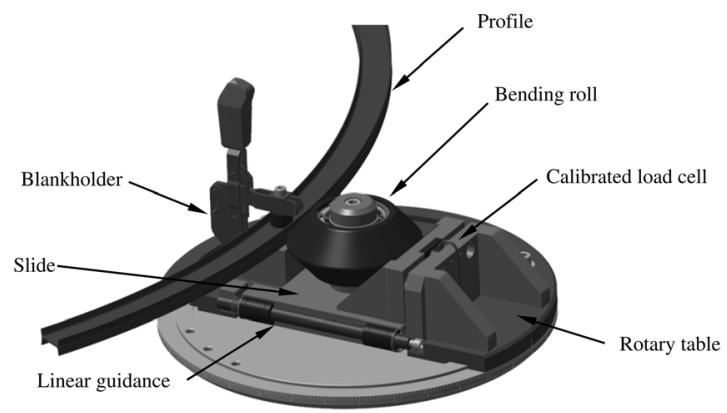

(a)

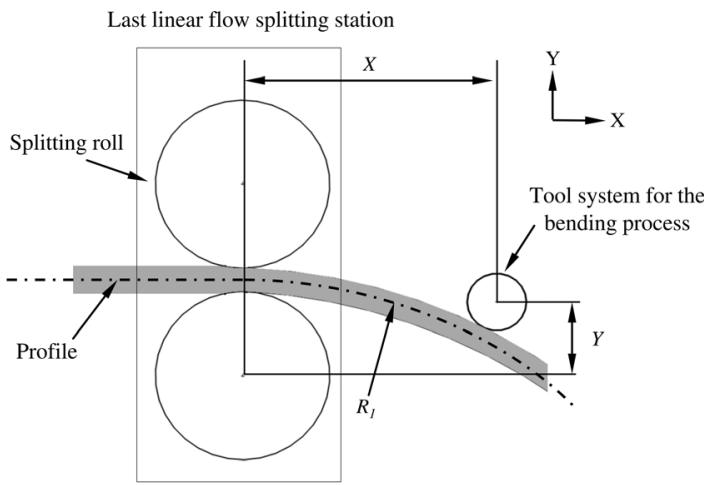

(b)

Fig. 5 Bending process (a) Tool system, (b) Schematic of variation of bending radius

The initial sheet width is $50 \mathrm{~mm}$. After 7 linear flow splitting operations, the width of the profile is reduced to $31 \mathrm{~mm}$. The thickness of the initial metal sheet is $2 \mathrm{~mm}$. The speed of the metal sheet is $3 \mathrm{~m} / \mathrm{min}$ in all experiments. The values of $X$ and $\mathrm{Y}$ as well as the process parameters chosen for the experiments are given in Table 1 (a) and (b).

\section{Numerical and analytical approach}

\section{Numerical model}

A numerical model of the bending process is created with a FE-software package Marc Mentat 2012 as shown in Fig. 6. The model is created using PYTHON scripts to achieve consistency in the geometries and solved with an implicit quasistatic solver. In this model, the last linear flow splitting operation and the bending process are considered. The geometry of the profile before the last stand is measured by a laser triangulation system. This geometry is considered as an initial geometry for the profile. The process parameters for the numerical model are same as in experiments which are described in Table 1 (b).

The profile in the FE model is axisymmetric in thickness direction as shown in Fig. 7. Material data for flanges and web are derived from experimental hardness measurements and fitted in Hollomon's equation $k_{f f \text { flange }}=1250 \varepsilon^{0.02}$ and $k_{f, w e b}=951 \varepsilon^{0.02}$. As a characteristic of linear flow splitting processes, flanges possess higher strength than the material in the web because of high plastic strains $[13,14]$. All the rolls are defined as analytical rigid bodies because of their high stiffness. The model is simulated using Coulomb friction model with a coefficient of friction as 0.12 between rolls and the profile. The contact is established by a node-to-segment contact algorithm which is successfully applied for a large variety of contact problems [25]. The model uses 8node hexagonal element with an assumed strain formulation. This element has an ability to capture a pure bending using a single element over the thickness. Therefore, the profile is meshed with one element over the thickness at the web region as shown in Fig. 6. Thermal effects are neglected.
Table 1 (a) Position of the bending tool, (b) Process parameters

\begin{tabular}{llc}
$X(\mathrm{~mm})$ & $Y(\mathrm{~mm})$ & $\begin{array}{c}\text { Bending radius } \\
R_{I}(\mathrm{~mm})\end{array}$ \\
425.36 & 100 & 600 \\
546.01 & 100 & 1000 \\
644.46 & 100 & 1400 \\
729.74 & 100 & 1800 \\
806.06 & 100 & 2200 \\
$\mathrm{~b}$ & & \\
Process Parameter & Value \\
Velocity of the metal sheet, $V_{\text {sheet }}$ & $3 \mathrm{~m} / \mathrm{min}$ & \\
Initial sheet width, $b_{\text {initial }}$ & $50 \mathrm{~mm}$ & \\
Width of the profile before bending, $b_{n-1}$ & $34 \mathrm{~mm}, 35 \mathrm{~mm}$ & \\
Incremental depth at the last station, $y_{\text {inc }}$ & $1.5 \mathrm{~mm}, 2 \mathrm{~mm}$ & \\
Total incremental depth, $y_{\text {total }}$ & $9.5 \mathrm{~mm}$ & \\
\hline
\end{tabular}




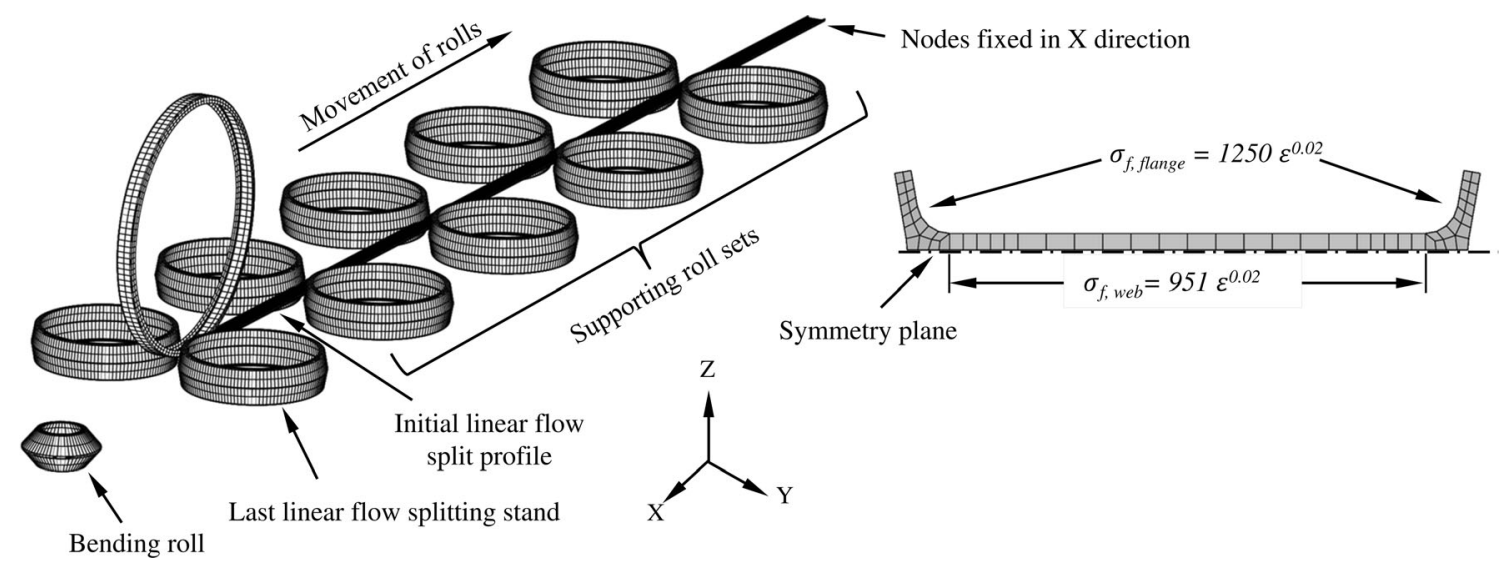

Fig. 6 FE model of bending process

The length of the sheet is taken as $2500 \mathrm{~mm}$ to achieve the steady state condition. To reduce the computational time, the end part of the sheet is fixed in $\mathrm{X}$ direction and rolls move across the sheet to retain the relative motion. Additional supporting roll sets are required to hold the profile in Y-direction. These rolls do not perform any forming. The bending roll is first moved in transverse and in longitudinal direction until it reaches a designed position for a specific bending radius (Fig. 5 (b)). After reaching the specific position, it is moved only in longitudinal direction until the end of the simulation. All rolls are free to rotate about their own axis due to friction between the sheet and the rolls.

\section{Numerical investigation of the forming zone}

The linear flow splitting process induces high stresses in the forming zone. These contribute to plasticization of the entire web portion of the profile as shown in Fig. 7 (a). Due to reduction in the width of the profile, tensile longitudinal strains are developed in the profile. To analyse the bending process after the linear flow splitting process, longitudinal strains are plotted along four paths in the profile as shown in Fig. 7 (b).

At path 1, just before the profile width reduction, material on both sides is compressed. At this position the longitudinal strain distribution is almost symmetrical. The longitudinal strain distribution becomes asymmetrical after path 2 which is a characteristic of a bending process where the inner side is compressed and the outer side is stretched. Therefore, it can be stated that the bending of the profile evolves after path 2 . At position of path 3 where the boundary of the plasticized zone ends, the longitudinal strain distribution at the outer side and inner side are almost similar to distribution at path 4 . This confirms that the bending operation takes place entirely within the forming zone induced by the flow splitting station.

As bending takes place in the forming zone, it is important to analyse the longitudinal stress distribution along path 3 .
The longitudinal stresses are plotted for profiles with bending radii of $1400 \mathrm{~mm}$ and $2200 \mathrm{~mm}$ along with a straight linear flow split profile as shown in Fig. 8.

It can be seen that, the linear flow splitting process introduces high symmetrical longitudinal compressive stresses in the forming zone. Because of the bending operation this distribution becomes asymmetrical. The difference between longitudinal stresses for bent profiles and the straight linear flow split profile can be attributed to the bending process. However, these additional bending stresses are small compared to the equivalent stresses $(1100 \mathrm{~N} / \mathrm{mm} 2)$ acting in the forming zone. To confirm this fact, the yield locus for a point on the outer edge of path 3 is plotted for linear flow splitting and combined bending with linear flow splitting as shown in Fig. 8 (b). For comparison, the stress state at the same position is also plotted in case of the three roll bending process (method A) which is described in Section 3. A. It can be seen that the stress state on the yield locus does not vary by a considerable margin when bending is combined with the linear flow splitting process. This difference is higher when three roll bending is considered. This proves that small changes in the stress state are sufficient to change strain components in the forming zone of the profile which also justifies lower magnitude of forces exerted on the bending roll.

\section{Analytical model}

An analytical approach allows to estimate the bending moment of the process and to support the layout of the tooling system. The linear flow split profile is an axisymmetric profile with a web and flanges which can be idealized by a double Tprofile as shown in Fig. 9a. As explained in the previous section, in the linear flow splitting process, the profile undergoes plastic deformation in the web (as seen in Fig. 2 b) resulting in various plastic and elastic zones within the crosssection of the profile. Therefore, the cross-section of the profile is divided into different sections with idealized and section 


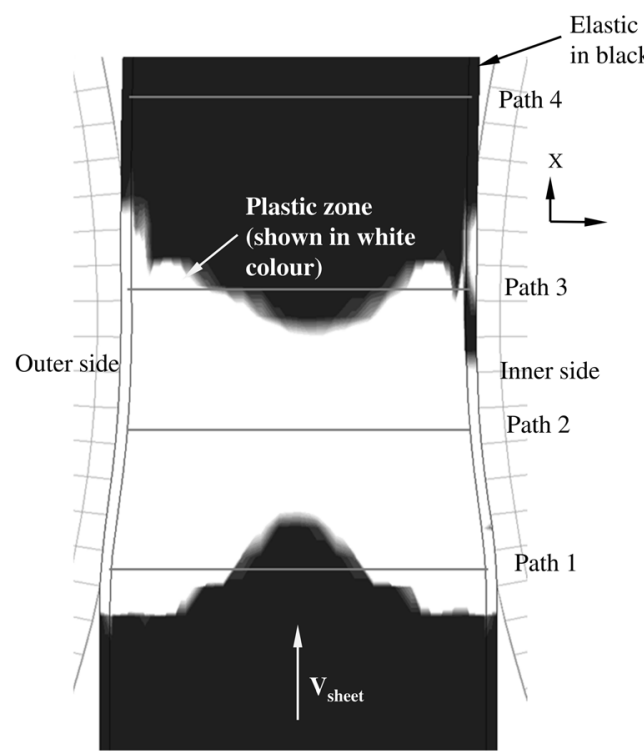

(a)

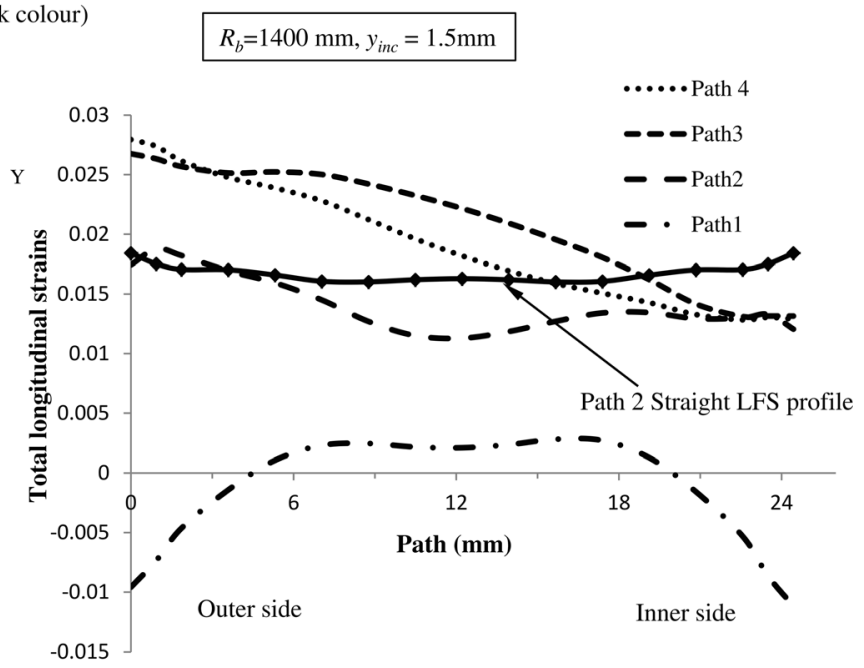

(b)

Fig. 7 a Forming zone in the profile, $\mathbf{b}$ distribution of longitudinal strains

dependent material properties. The size of these sections is dependent on geometrical properties, incremental in-feed $y_{i n c}$ and total in-feed $y_{\text {total }}$. The numerical model explained in the previous section can be used for the calculation of the size of these sections. For analytical calculation of the bending moment $M_{b}$, pure bending is assumed. The bending moment $M_{b}$ is calculated separately for each rectangular section of the profile as shown in Fig. 9 (b).

Equations are derived for a profile with assumptions of Chatti [21] regarding shape, induced strain and material properties. For sections 1, 2, and 3 (Fig. 9 (b)), the bending moment for the whole outer solid section is calculated and the solid inner section (dashed) is subtracted from each corresponding section. The total bending moment is the sum of moments of all sections. Sections 2 and 3 are assumed to have ideal elastic-plastic properties compared to sections 1 and 4 with an ideal elastic property only. Thus, bending moments for sections 2 and 3 are the sum of elastic and plastic bending moments which can be calculated for a rectangular crosssection from Eq. 1:

$\mathrm{M}_{\mathrm{b}}=\frac{2}{3} \mathrm{k}_{\mathrm{f}} \mathrm{b}_{\mathrm{n}} \mathrm{y}_{\mathrm{F}}^{2}+\mathrm{k}_{\mathrm{f}} \mathrm{b}_{\mathrm{n}}\left(\frac{\mathrm{h}_{\mathrm{n}}^{2}}{4}-\mathrm{y}_{\mathrm{F}}^{2}\right)$

In eq. $2, y_{F}$ is the distance from neutral axis to the boundary between the elastic and plastic section, $k_{f}$ is the flow stress of the material, $b_{n}$ and $h_{n}$ are widths and heights of the corresponding sections, and $R_{b}$ is the bending radius. The bending moment is calculated with a substitute young's modulus $E_{\text {sub }}$ for sections 1 and 4 which are characterised by an ideal elastic behaviour.

$$
\mathrm{M}_{\mathrm{b}}=\frac{\mathrm{E}_{s u b} \mathrm{~J}_{\mathrm{z}}}{R_{\mathrm{b}}}=\frac{\mathrm{E}_{s u b} \mathrm{~b}_{\mathrm{n}} \mathrm{h}_{\mathrm{n}}^{3}}{12 \mathrm{R}_{\mathrm{b}}}
$$

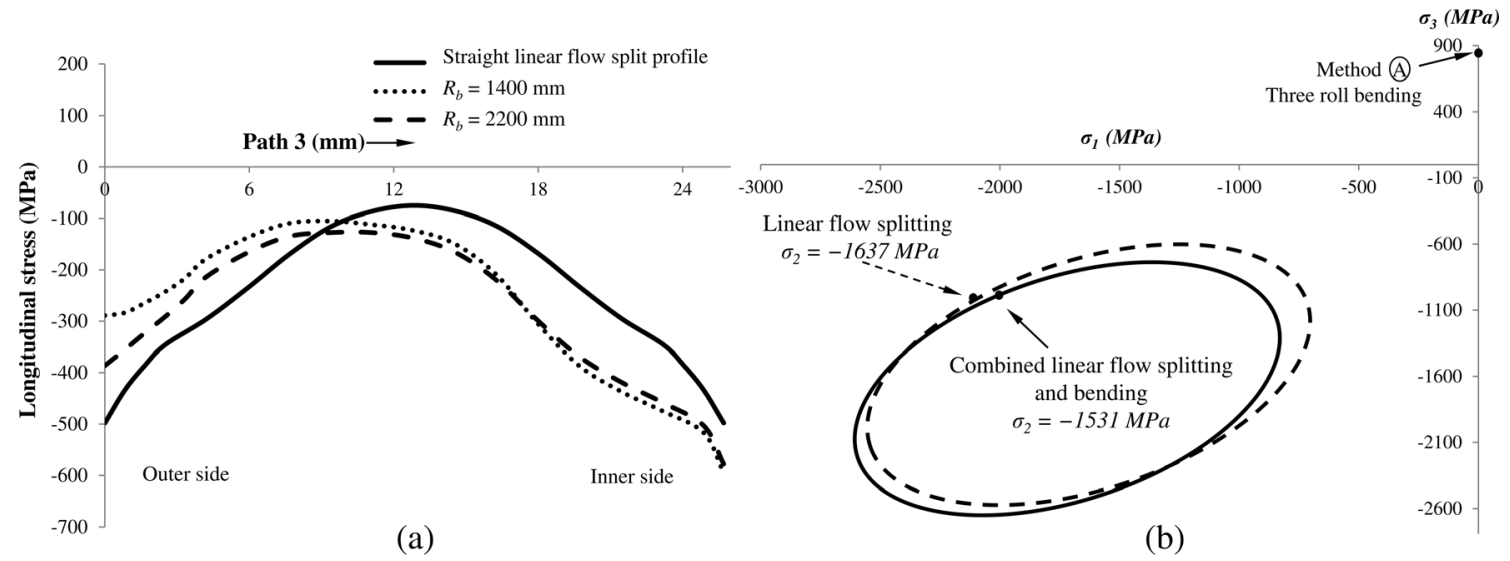

Fig. 8 a Longitudinal stresses in the forming zone, b Stress states in methods A and D 


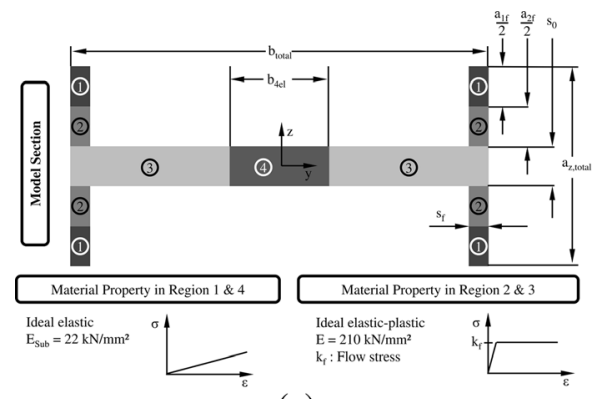

(a)

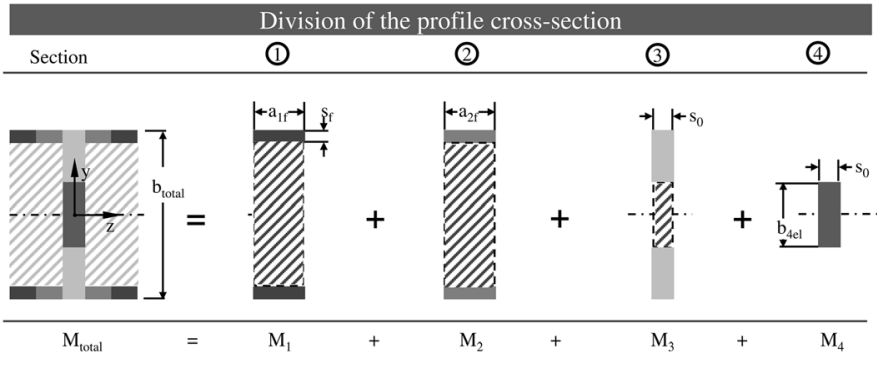

(b)

Fig. 9 a Assumptions in the analytical model, b Division of the profile cross-section

In eq. $3, J_{z}$ is moment of area for sections 1 and 4 . To calculate individual bending moments for sections 1 to $4, b_{n}$ and $h_{n}$ are substituted by $a_{1 f}, a_{2 f}, s_{0}$ (for sections 3 and 4) and $s_{f}$ (for sections 3 and 4 ), $b_{\text {total }}-b_{4 e l}, b_{4 e l}$ respectively where $a_{1 f}$ and $a_{2 f}$ are the widths of the flange in sections 1 and 2 . The thickness of web is equal to the width of section $3, s_{0}$ whereas $s_{f}$ is the thickness of the flange. The total width of the profile is $b_{\text {total }}$ whereas $b_{e l}$ is the height of section 4 as shown in Fig. 9 (b).

The resulting cross section of the profile in the presented investigation has a width $b_{\text {total }}=31 \mathrm{~mm}$ and a flange width of $a_{z \text {,total }}=13 \mathrm{~mm}$ with the thickness of the web $s_{0}=2 \mathrm{~mm}$ and the thickness of the flange $s_{f}=1 \mathrm{~mm}$. These dimensions are calculated from results obtained from experiments and numerical analysis. Other dimensions of the sections are dependent on the incremental in-feed. The accurate choice of these dimensions is necessary to validate analytical with experimental results. From numerical analysis, it was found that widths of sections 1 and 2 are $a_{1 f}=0.6 \mathrm{~mm}$ and $a_{2 f}=10.4 \mathrm{~mm}$ respectively whereas the height of zone $4\left(b_{4 e l}\right)$ is $8 \mathrm{~mm}$ for $y_{\text {inc- }}$ $=1.5 \mathrm{~mm}$. At an increased in-feed of $y_{i n c}=2 \mathrm{~mm}$, the plastic zone increases and it was found that the web is fully plasticised resulting in $b_{4 e l}=0 \mathrm{~mm}$. Zone 1 also decreased with $a_{1 f}=0.4 \mathrm{~mm}$ and $a_{2 f}=10.6 \mathrm{~mm}$. From tensile tests of RAWAEL 80 , initial yield stress is determined as $k_{f}=840 \mathrm{~N} / \mathrm{mm} 2$.

\section{Bending moment}

The experiments are performed using different incremental infeeds $y_{\text {inc }}$ of $1.5 \mathrm{~mm}$ and $2 \mathrm{~mm}$ keeping total in-feed constant at $y_{\text {total }}=9.5 \mathrm{~mm}$. Bending moment is determined by multiplying the measured force and the perpendicular distance from the bending zone to the bending roll. The experimental results show a decrease in bending moments with an increase of the bending radius for both incremental in-feeds (Fig. 10). The intensity of reduction of bending moment decreases with an increase in bending radius.

A good correlation can be seen between the analytical model, the FEA and the experimental results. The curve for analytical results decreases with increasing in-feed $y_{\text {inc }}$. The increase in in-feed and the plastic zone is described in the model with a decrease of size of zones 1 and 4 with corresponding increase of size of zones 2 and 3 . As shown in the graphs, there is a variation of the experimental results displayed as error indicators. This is a result of the tumbling movement of the linear flow splitting stands which is described by Vucic [3].

\section{Profile properties}

In classical edgewise bending, the profile tends to thicken at the inner side of the bent profile as the bending radius decreases [19]. This effect is not noticed when superposing
Fig. 10 Effect of process parameters on the bending moment

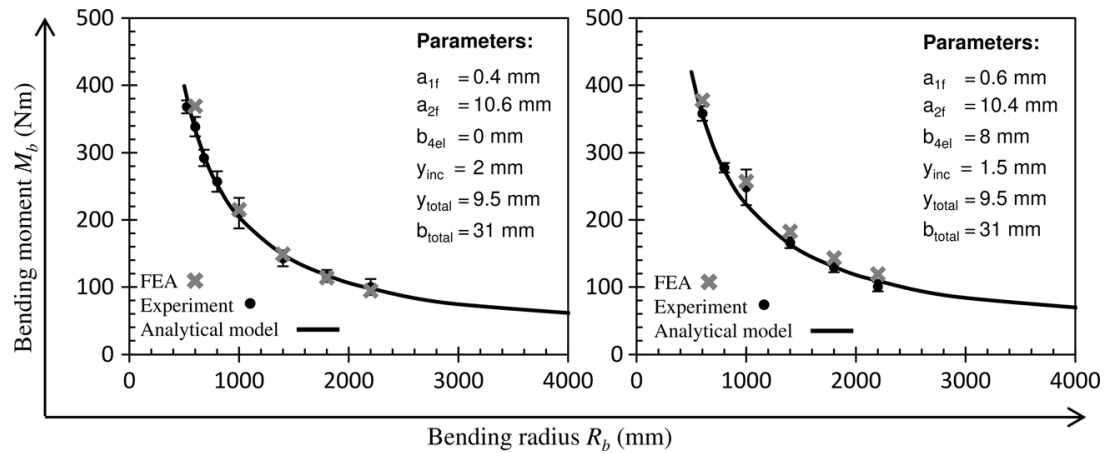




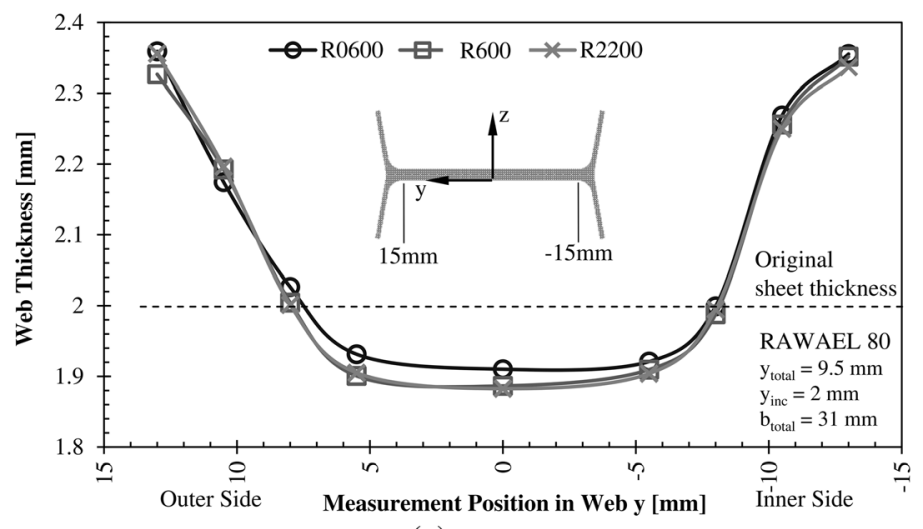

(a)

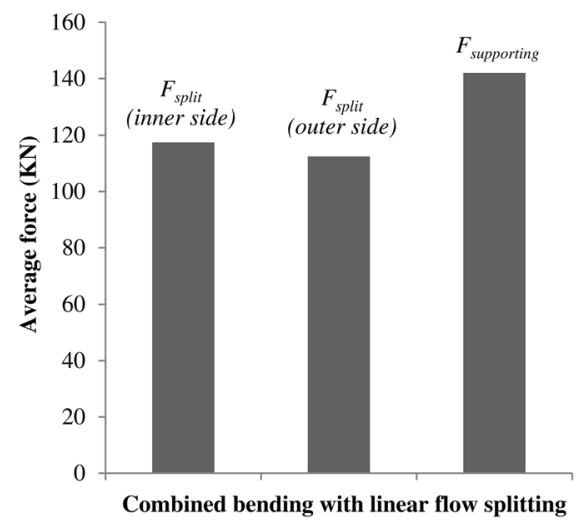

(b)

Fig. 11 a Measurement of the thickness of the web after bending, b Forces exerted on rolls

linear flow splitting and bending process. The thickness of the web (Fig. 11a) shows the typical shape of linear flow splitting profile with thinning in the middle and thickening on the edges near to the splitting zone.

The bending takes place in the forming zone of a linear flow splitting process. Therefore, any additional thickening of the profile due to bending is rolled out by the supporting rolls of the linear flow splitting station. Consequently, higher forces are exerted on rolls of the linear flow splitting station in the forming zone as shown in Fig. 11b.

Therefore, there is no change in the thickness of the web after bending process.

The variation of the bending radius also has no influence on the resulting angle between the flanges, the wing span of the flanges and the distance between the splitting centres. All these geometrical properties as well as the bending radius $R_{b}$ are found to be reproducible.

The surface roughness at the splitting centre is investigated. The variations of both measurements $(0.2 \mu \mathrm{m})$ overlap, as the surface roughness of the bent profile is $R_{z}=0.84 \mu \mathrm{m}$ while the roughness of the straight profile is at $R_{z}=1.16 \mu \mathrm{m}$. There is no difference in the results between outer and inner side of the bent profile. The inspection of the surface also showed no cracks at the surface of the profile.

\section{Conclusion and outlook}

The investigations show that the continuous bending of linear flow splitting profiles is possible with high flexibility to accommodate changes in the bending radius. The most promising method for bending linear flow split profiles is the superposition of linear flow splitting process with a bending process. Analytical and FE models are put forward for calculating the bending moment which are found to be beneficial in designing a tooling system.
The analytical model predicts the bending moment within the average experimental deviation of $\Delta M_{b} \approx 6 \%$, whereas the FE model predicts with maximum error of $1 \%$. Results show that the bending moment and resulting bending forces can be influenced by the choice of the incremental in-feed in the linear flow splitting station.

The bent profile's geometrical properties of the cross section are similar to a straight profile. Combining this fact with the reproducibility of the bending radii makes bending of linear flow splitting profiles suitable for continuous production.

Acknowledgment The investigations presented in this paper are supported by the German Research Foundation (DFG). The authors would like to thank DFG (Die Deutsche Forschungsgemeinschaft) for funding the Collaborative Research Centre 666 "Integral sheet metal design with higher order bifurcations - Development, Production, Evaluation”.

\section{Compliance with ethical standards}

Funding This study was funded by Deutsche Forschungsgemeinschaft (GZ: SFB666/2 T1).

Conflict of interest The authors declare that they have no conflict of interest.

Open Access This article is distributed under the terms of the Creative Commons Attribution 4.0 International License (http:// creativecommons.org/licenses/by/4.0/), which permits unrestricted use, distribution, and reproduction in any medium, provided you give appropriate credit to the original author(s) and the source, provide a link to the Creative Commons license, and indicate if changes were made.

\section{References}

1. Groche P, Vucic D (2006) Multi-chambered profiles made from high-strength sheets. Product Engineering, Annals WGP 3: 67-70 
2. Growth Opportunities for Advanced High-Strength Steel in the Global Automotive Industry 2014-2019, online [1] www. prnewswire.com/news-releases, Accessed 12 March 2015

3. Groche P, Ringler J, Vucic D (2007) New forming processes for sheet metal with large plastic deformation. Key Engineering Mat 344:251-258

4. Statistisches Bundesamt (2013) Erzeugung von Rohstahl, Walzstahl, Stahlrohren, Tabelle 42311-0001. Statistic, online [2] www genesis.destatis.de/genesis/online, Accessed 26 August 2013

5. Groche P, Vucic D, Jöckel M (2006) Basics of linear flow splitting. J Mater Process Technol 183:249-255

6. Görtan M, Vucic D, Groche P, Livatyali H (2009) Roll forming of branched profile. J Mater Process Technol 209:5837-5844

7. Taplick C, Rullmann F, Groche P (2010) Further processing of UltraFine-grain materials. Int J Mater Form 3(1):833-836

8. Taplick C, Schmitt S, Rullmann F, Ludwig, C Groche, P (2011) High Strength Hydroformed Steel Profiles with Free Flanges, steel research international, Wiley-VCH Verlag, Special edition: 10th International Conference on Technology of Plasticity (Special Edition), 487-492

9. Lungwitz C (2013) 20 Jahre Audi Space Frame - Siegeszug begann auf der IAA. www.audi.mediaservices.com Accessed on 9 April 2015

10. Bambynek A (2001) Flurfreie Fördersysteme im automatischen Materialfluss. Technische Universität München, Dissertation

11. General Electric (2013) GE developing fabric-based turbine blades. Reinf Plast 57(1):5
12. Müller C, Bohn T, Bruder E, Groche P (2008) UFG microstructures by linear flow splitting. Materials Sci Forum 584-586:68-73

13. Kaupper M (2012) Biegen von höherfesten Stahlblechwerkstoffen - Umformverhalten und Grenzen der Biegbarkeit. Universität Erlangen-Nürnberg, Dissertation

14. Hermes M, Chatti S, Weinrich A, Tekkaya AE (2008) Three dimensoinal bending of profiles with stress superposition. Internl J Mat Form, Suppl 1:133-136

15. N N (2014) Den Bogen raus. Blech Rohre Profile, Issue 2:78-79

16. VDI 3430: Richtlinie, Rotationszugbiegen von Profilen. Verein Deutscher Ingenieure e.V. (2014) Düsseldorf

17. Ludwik P (1903) Technologische Studie über Blechbiegung - Ein Beitrag zur Mechanik der Formänderungen. Technische Blätter 35: 133-159

18. Lange K (1990) Handbook of Metal Forming - Volume 3

19. Oehler G (1967) Hochkantbiegen von Blechen. Forschungsberichte des Landes Nordrhein-Westphalen, Köln und Opladen

20. Chatti S (1998) Optimierung der Fertigungsgenauigkeit beim Profilbiegen. Technical University of Dortmund, Dissertation

21. Marc (2012) Product documentation: element library, Vol. B

22. www.waelzholz.com/en/steel-materials/high-strength-steel-strip. html Accessed 11 May 2016

23. Abaqus (2013) Abaqus 6.13 Documentation, 2013

24. George T. Halmos (2005) Roll forming handbook

25. Marc (2012) Product documentation: theory and user information, Vol. A 